\title{
ESTUDO COMPARATIVO EXPERIMENTAL DA ESTENOSE ESOFAGOGÁSTRICA NAS SUTURAS MANUAL E MECÂNICA
}

\section{EXPERIMENTAL COMPARATIVE STUDY OF ESOPHAGOGASTRIC STENOSIS IN MANUALAND MECHANIC SUTURES}

\author{
Francisco Américo Fernandes Neto,TCBC-SP ${ }^{1}$ \\ José Luiz Braga de Aquino, TCBC-SP ${ }^{2}$ \\ Cirilo Luiz de Pardo Mero Muraro, TCBC-SP ${ }^{2}$ \\ Roberto Rubem Pando Serrano ${ }^{3}$ \\ Abrão Rapoport, TCBC-SP ${ }^{4}$ \\ Mario Mantovani, TCBC-SP5
}

\begin{abstract}
RESUMO: Vinte e oito porcos foram aleatoriamente separados em dois grupos de 14 animais (A e B). Operados, o diâmetro anatômico das respectivas cárdias foi moldado e medido por um balonete de látex distendido por injeção de alginato, seguida de seção esofagogástrica. As anastomoses do grupo "A" foram realizadas ponto a ponto com fio de poliglactina 910-“000" e as do "B"com grampeadores "ILS". Sete animais dos subgrupos "A1"e"B1" foram reoperados e estudados após sete dias e outros sete porcos, dos subgrupos "A 2" e "B 2", foram no 14을. As peças anatômicas foram macroscopicamente examinadas, submetidas à prova pressórica, histologicamente estudadas, e os moldes, identificados e aferidos. Realizou-se estudo comparativo, prospectivo e randomizado da diferença percentual média de estenose ("delta P”), obtida pela média dos diâmetros da cárdia antes e após sutura manual e mecânica. A análise estatística demonstrou insignificante variação na diferença de estenoses e dos tempos operatórios ("deltas Ps"). Na sutura manual, o "delta P" foi $25,44 \%$ no sétimo dia pós-operatório e $15,88 \%$ no 14 dia e na mecânica, os percentuais do grupo de sete e 14 dias, respectivamente, foram 22,80\% e 23,04\%. As estenoses não prejudicaram o trânsito alimentar esofagogástrico. Macroscopicamente não houve vazamentos em cavidade livre apesar da microscopia ter evidenciado deiscências parciais bloqueadas em três animais. As aderências foram mais incidentes no grupo de sutura manual e a má coaptação das bordas viscerais, em alguns grampeamentos, resultou em cicatrização fibrótica com estenose mais acentuada. A sutura manual causou maior reação flogística perianastomótica e o grampeamento comprometeu mais intensamente a mucosa e a neo-angiogenêse. $\mathrm{O}$ trabalho parece ter demonstrado que as suturas manual e mecânica, se não são ideais, são satisfatórias e de considerável qualidade quando realizadas com mínimo traumatismo, boa hemostasia, preservação do aporte sangüíneo, controle de infeção, escolha do fio ou do grampeador apropriado e a adequada coaptação das margens viscerais.
\end{abstract}

Unitermos: Estenose esofagogástrica; Sutura manual e mecânica.

\section{INTRODUÇÃO}

A controvérsia sobre suturas não é recente, pois desde 3500 a.C., através de pergaminhos egípcios ${ }^{1}$ e há 2500 a.C. pelo "Papiro Cirúrgico de Smith", as discussões per- sistem até nossos dias. No fim do século passado, Halsted ${ }^{3}$ (1887) demonstrou, em estudos experimentais, ser imprescindível a inclusão da camada submucosa nas anastomoses intestinais e preconizou a sutura em plano único, envolvendo as camadas serosa muscular e submucosa.

1. Mestre em Cirurgia de Cabeça e Pescoço do Hospital Heliópolis, Hosphel - SP

2. Doutor em Medicina da UNICAMP - SP

3. Doutor em Cirurgia Experimental da UNIFESP.

4. Professor Docente Livre da USP.

5. Professor Titular de Traumatologia da UNICAMP.

Recebido 14/9/99

Aceito para publicação em 6/12/99

Trabalho realizado no Serviço de Cirurgia do Hospital Celso Pierro da PUCCAMP - São Paulo. 
Todavia, a sutura em plano único não foi bem recebida pelos cirurgiões, que optaram pela dupla rafia intestinal ${ }^{3,4}$.

De maneira geral, as anastomoses manuais são feitas em plano único chuleado ${ }^{4-6}$, em um plano ponto a ponto ${ }^{7,8}$, em dois planos ou ancorada ${ }^{9}$, telescopada e envolvida em "laço de gravata", telescopada com a mucosa invagina$\mathrm{da}^{10}$, sendo utilizadas através de combinações de fios absorvíveis e inabsorvíveis ${ }^{11,12}$.

Para as anastomoses esofagianas, são empregadas suturas manual e mecânica, onde a sua vascularização, a inexistência de serosa, a presença de maior tensão e tração das suturas ${ }^{13}$, justificam a incidência de complicações (fístulas, deiscência, lacerações e estenoses).

Quanto à sutura mecânica idealizada em 1826 por Denans ${ }^{14}$, após anos de uso probatório, mudou radicalmente da máquina de grampear, idealizada em 1921, para o uso em 1970 de grampeadores PK 25 com grampos de tântalo ${ }^{16}$. Entre nós, em 1981, estudaram-se anastomoses esofagojejunais com um aparelho EEA (End to End Anastomosis), com $26,6 \%$ de deiscência e enquanto que com a sutura manual foi relatada 5,6\% de deiscência em 199017,18.

Assim, estudamos anastomoses esofagogástrica manuais e mecânicas na cárdia, em animais de experimentação (suínos), avaliando o diâmetro no pré e pós-operatório, utilizando molde de alginato revestido por látex, estudo da fibrose cicatricial relacionada a distância entre os lados da anastomose e a estenose encontrada ao lado da diferença percentual média da estenose do diâmetro anatômico e pós-operatório.

\section{MATERIAL E MÉTODOS}

Foram operados e estudados 30 porcos machos (Sus domesticus), aleatoriamente escolhidos entre mestiços resultantes do cruzamento de Landrace (macho) com Rayo White (fêmea), selecionados pela idade de 60 dias e pesando entre $17 \mathrm{~kg}$ e $19 \mathrm{~kg}$ (em média $17.800 \mathrm{~g}$ ). Dois animais foram reservados para se testar a viabilidade das respectivas técnicas experimentais a serem pesquisadas (manual e mecânica). Os restantes 28 animais foram, aleatoriamente, separados em dois grupos de 14 animais respectivamente.

O fio de poliglactina 910-“000" foi o material empregado na sutura manual. Na rafia mecânica usou-se o grampeador ILS de 21 milímetros. Os animais desta experimentação foram internados para adaptação no biotério do Laboratório de Técnica Operatória e Cirurgia Experimental da Pontifícia Universidade Católica de Campinas (PUC-CAMPINAS), quatro dias antes da data da operação. Todos foram previamente tratados com $400 \mathrm{mg}$ de Albendazol (dose única), devidamente identificados por plaqueta fixada na orelha e registrados no livro protocolar do experimento.

Separaram-se dois grupos de 14 animais. O primeiro grupo, denominado "A", era composto por animais submetidos à anastomose esofagogástrica manual, com pontos interrompidos com fio de poliglactina 910-“000” (Vicryl) , montados em agulha atraumática, passados na parede muscular e na submucosa esofagiana. No estômago os pontos interessavam o plano seromuscular e a submucosa. Estes eram eqüidistantes três milímetros. Não se usou eletrocautério para a hemostasia das bordas. Os animais do subgrupo "A 1" foram reoperados no sétimo dia pós-operatório e os do subgrupo "A 2", no 14 dia pós-operatório.

O segundo grupo, "B," era constituído por animais submetidos à anastomose esofagogástrica mecânica, com grampeador intraluminal (ILS- Intraluminal Staper) de 21 milímetros de diâmetro, carregado com 16 grampos de titânio que mediam 4,5 por 5,5 milímetros. Os animais "B1" foram reoperados no sétimo dia pós-operatório e os "B2" no 14ํ pós-operatório.

\section{Pré-operatório}

Após jejum pré-operatório de 24 horas e pesagem do animal no dia da cirurgia, iniciava-se a anestesia com indução com tiopental sódico na dose de $30 \mathrm{mg} / \mathrm{kg}$ de peso, administrando-se $2 \mathrm{~g}$ de Cefalotina EV. A anestesia era mantida com tiopental sódico e a analgesia era realizada com dipirona $2 \mathrm{ml} \mathrm{EV}$ após 1 hora de cirurgia. Também foram utilizados miorrelaxantes do tipo curare despolarizante - Brometo de Pancurônio 0,08 a 0,1 mg por quilo/peso.

Tricotomia do campo operatório, colocação do animal em decúbito dorsal horizontal (DDH), anti-sepsia com Iodo Polivinilpirrolidona (IPVP), e colocação de campos cirúrgicos assépticos.

\section{Ato Operatório}

Realizada incisão mediana xifoumbilical, com abertura plano por plano com hemostasia com termocautério e ligaduras vasculares com fio de algodão " 000 ”, efetuouse investigação sistematizada da cavidade celômica e introdução de cateter nasogástrica (SNG) no 16.

A seguir, procedia-se à mobilização gástrica após a liberação do ligamento triangular hepático esquerdo e afastamento do lobo ipsilateral para a direita, que era mantido afastado com o auxílio de pequena compressa úmida enrolada e a região hiatal era exposta. A membrana hepatogástrica era incisada para a exposição do esôfago. Esse era isolado com um dreno de Penrose pequeno, previamente umedecido com soro fisiológico. Realizava-se, então, uma incisão de aproximadamente 10 centímetros de extensão, oblíqua ao eixo maior esofagogástrico, paralela e distante cerca de $8 \mathrm{~cm}$ da cárdia (Figura 1). Por esta abertura, identificava-se visual e digitalmente o orifício esofagogástrico (transição) e introduzia-se no pertuito esofagogástrico um balonete desinflado, manufaturado com um segmento de sonda de Levine no 18 medindo 15 centímetros, contendo três fenestrações caudais pequenas e equiidistantes aproximadamente um centímetro, encoberto por um dedo de luva cirúrgica de látex, no 8 , referente ao indicador ou $2^{\mathrm{o}}$ quirodáctilo. $\mathrm{O}$ balonete envolvia os três quartos caudais da sonda e era firmemente amarrado na extremidade cefálica, com um fio de algodão " 000 ". Testava-se a sonda introduzida, injetando-se com uma seringa 15 centímetros cúbicos de ar. Uma vez inflado o 
balonete e confirmada sua localização transcárdica, esse era desinflado e reinflado com uma solução de alginato ("JELTRATE" - diatomida alginato de potássio + sulfato de cálcio + óxido de ferro+ tetrasódio pirofosfato + óleo de spearmint) $10 \mathrm{~g}$ diluídos em 25 centímetros cúbicos de água destilada. Após sete minutos, o molde da transição esofagogástrica, já bastante consistente, era delicadamente retirado, identificado e fotografado. Externamente a transição esofagogástrica era reparada lateral e medialmente com fio de algodão "000" . A cárdia era então seccionada com bisturi de lâmina 25 , tomando-se como reparo cirúrgico uma pequena veia, a qual denominou-se cardiotuberiositária, que percorre pequeno sulco da face anteromedial para a lateral, exatamente na projeção externa da linha de transição esofagogástrica. Separadas as extremidades esofágica e gástrica, essas, após hemostasia, eram anastomosadas.

Nos animais do grupo "A" as anastomoses foram realizadas de maneira manual, em pontos interrompidos, eqüidistantes aproximadamente três milímetros, com poliglactina "000"(Vicryl), interessando a parede muscular e muscular da mucosa esofágica e a seromuscular com a muscular da mucosa gástrica (pontos extramucosos).

Os animais do grupo "B" foram submetidos à anastomose esofagogástrica com grampeadores ILS de $21 \mathrm{mi}-$ límetros de diâmetro externo, que também serviam de guia para a ascensão gastroesofágica (Figura 2). Nessa modalidade, inicialmente confeccionou-se uma sutura em bolsa com polipropileno (prolene) " 0000 ", envolvendo a cabeça e o trocarte do grampeador, para possibilitar a aposição e coaptação das extremidades viscerais a serem anastomosadas. Depois de devidamente ajustadas ambas as extremidades, certificava-se da não existência de excesso de tecido interposto e efetuava-se o disparo do grampeador. Simultaneamente, dois tempos operatórios eram efetuados pelo grampeador: a anastomose mecânica e a ressecção do excesso de tecido interposto. Essa última fase era evidenciada pelos anéis de tecido ressecado presentes na ogiva e na bigorna do aparelho de sutura respectivamente. O resultado era uma anastomose término-terminal em dois planos com eversão das bordas. A zona anastomosada era inspecionada em busca de falhas. Cuidadosamente a cabeça do grampeador era recuperada e examinada junto com a bigorna para identificação dos anéis resultantes da secção e anastomose esofagogástrica. Finalmente, era feito o fechamento da gastrotomia, anteriormente utilizada para a introdução da "sonda-molde" e do grampeador, com fio de poliglactina 910-“000”(Vicryl) em sutura contínua (chuleio) em um plano. Revisão da hemostasia e fechamento de todos os planos da parede abdominal.

\section{Pós-operatório}

$\mathrm{O}$ animal era mantido com dieta hídrica nas primeiras horas do pós-operatório e dieta geral (ração) após 24 horas, ao lado de analgesia com dipirona $2 \mathrm{ml}$ e Tenoxican $40 \mathrm{mg}$. -EV - no pós-operatório imediato.

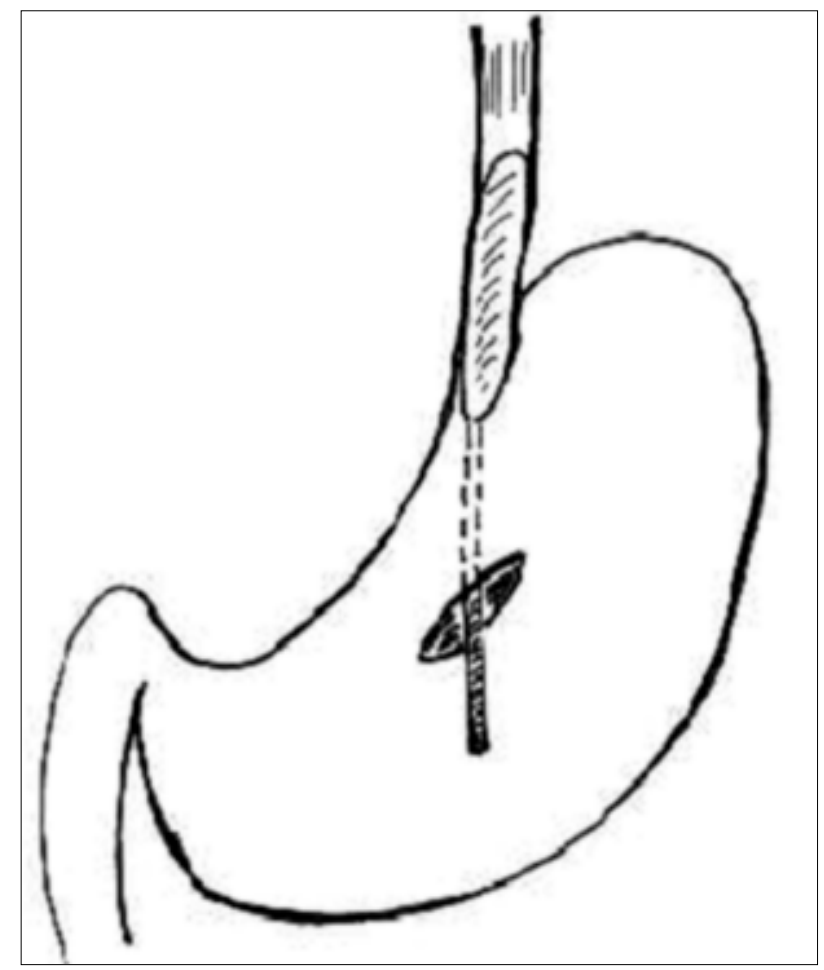

Figura 1 - Gastrostomia e manejo da sonda-molde na medição do diâmetro da cárdia.

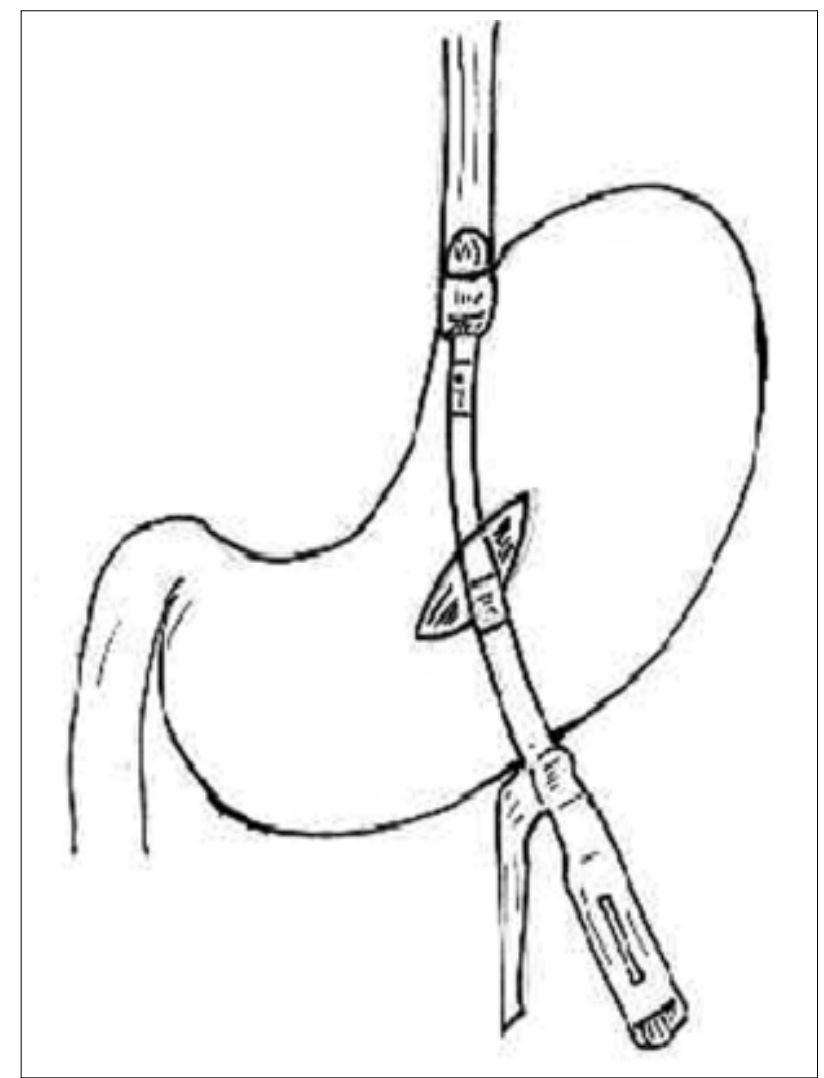

Figura 2 - Utilização do grampeador na anastomose esofagogástrica. 


\section{Avaliação Geral e Cirúrgica dos Animais de Pesquisa}

Os animais submetidos a ambas as técnicas de sutura (manual e mecânica) foram reoperados em sete e 14 dias, e pesquisava-se a existência de eventos intracavitários, principalmente perianastomóticos, tais como: fístulas, deiscências, abscessos e o grau de aderências. Nesta ocasião, o corpo gástrico era reaberto sobre a cicatriz da gastrotomia e do animal ainda vivo, sob anestesia, obtinha-se novo molde de JELTRATE da região anastomosada. O esôfago era seccionado há cerca de cinco centímetros acima da cárdia e o estômago no nível da abertura corporal anteriormente realizada. Sacrificavam-se os animais, após a retirada da peça anatômica, utilizando infusão endovenosa de tiopental sódico $240 \mathrm{mg}$ associado a $100 \mathrm{mEq}$ de cloreto de potássio.

\section{Avaliação dos Moldes das Anastomoses Cárdicas}

Os moldes de JELTRATE, referentes às medições pré e pós-operatória, foram seccionados com uma lâmina de micrótomo, exatamente no sulco anatômico referente à transição esofagogástrica facilmente identificável (Figura 3). As secções transversas foram aferidas com paquímetro milimétrico digital, fotografadas e devidamente registradas no livro protocolar da experiência.

\section{Avaliação Macroscópica e Microscópica das Peças Anatômicas}

As peças anatômicas, correspondentes aos segmentos esofagogástricos anastomosados, foram exa- minadas e submetidas ao teste de vazamento. Para isso fechava-se a extremidade caudal das peças, mergulhava-as na água e em seguida as inflava com ar comprimido, fluxo de cinco litros p/ minuto injetado através do segmento esofagiano (Figura 4). Observava- se a ocorrência de bolhas aéreas ou rupturas da linha de sutura. Após tal procedimento, as peças eram abertas pela borda medial e inspecionava-se a zona de sutura externa e interna. Verificava-se a existência de restos de fio de sutura, de grampos, granulomas, abscessos, fístulas, ulcerações e deiscências. Identificadas e fotografadas, as peças eram estendidas em um anteparo de isopor e fixadas com solução aquosa de formol a $10 \%$ para conservação e futura análise microscópica.

A microscopia constituiu-se na fixação das peças com formol a $10 \%$, inclusão em parafina e coloração dos cortes histológicos pela hematoxilina-eosina (HE). Este estudo pesquisou a presença de: a) fenômeno isquêmico caracterizado pela necrose, ulcerações, deiscências, fístulas, hemorragia e edema; b) neo-angiogenese c) inflamação aguda ; d) granuloma tipo corpo estranho; e) quantidade de tecido conjuntivo de reparação, avaliado pelo método de coloração da HE e tricrômico de Masson relacionado a distância entre as margens anastomóticas.

\section{Avaliação Estatística}

Foram analisadas as variáveis: diâmetros pré e pósoperatório da cárdia, tempo operatório em minutos, peso do animal e aderências. Foi criada, ainda, uma nova variável, denominada "delta P", que representa a diferença percentual média entre os diâmetros pré e pós-operatórios e a dos tempos operatórios. Para fins da análise estatística calculou-se a média, o desvio-padrão, a freqüência e empregou-se os testes não paramétricos: "Exato" de Fisher e "T" de Wilcoxon de diferença de médias.

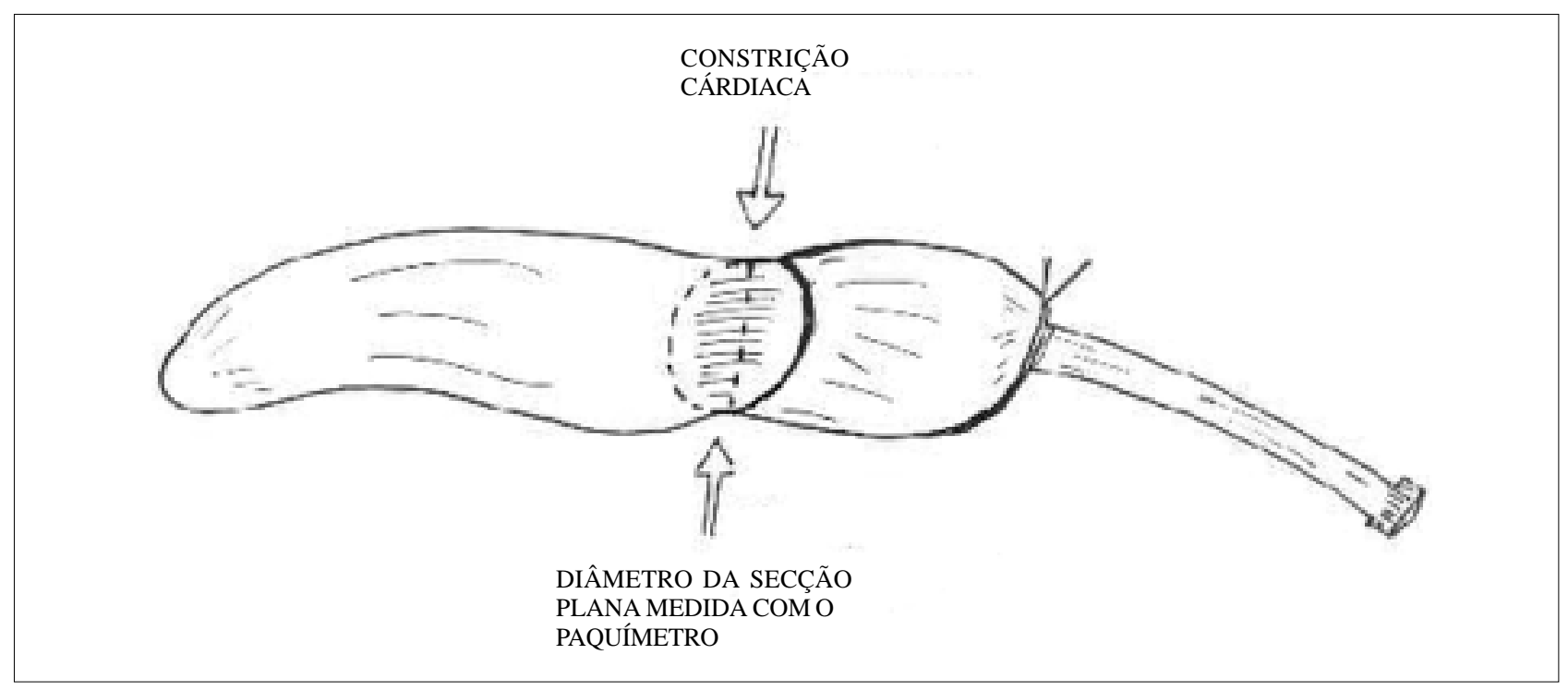

Figura 3 - Seção transversa, no molde de alginato, da constrição cárdica. 


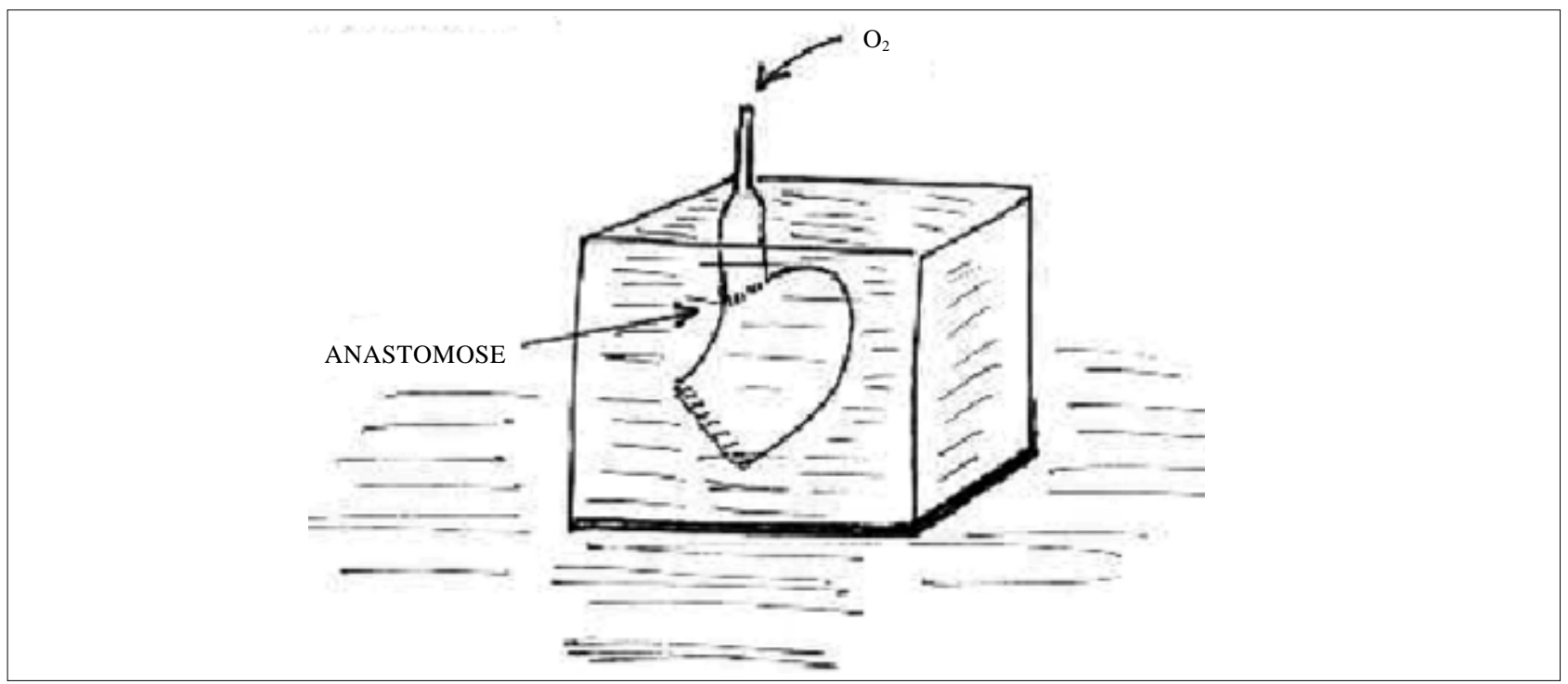

Figura 4 - Prova de imersão e injeção de $\mathrm{O}_{2}$ nas peças anastomóticas.

\section{RESULTADOS}

Ocorreram dois óbitos no período intra-operatório: um por hipoxia devido a acidente de anestesia e outro por choque hipovolêmico decorrente de lesão inadvertida da veia porta. Ambos os animais foram excluídos da pesquisa. As demais operações transcorreram sem acidentes. Nas reoperações, apesar do jejum pré-operatório, era freqüentemente observada a quantidade de resíduos alimentares (ração) na câmara gástrica.

No pós-operatório ocorreu um óbito devido à evisceração conseqüente do erro de técnica operatória durante o fechamento da parede abdominal. $\mathrm{O}$ animal não foi considerado para o experimento. Os demais animais não apresentaram nenhuma intercorrência clínica no pós-operatório. Todos ingeriam água no primeiro dia de pósoperatório e alimentavam-se com ração no segundo dia pós-operatório.

Não foram observados vazamentos ou rupturas em nenhuma anastomose quando submetidas à inspeção visual desarmada e à prova subaquática de enchimento aéreo.

\section{Exame Anatomopatológico}

No exame macroscópico não se observou nenhum vazamento (fístulas e deiscências) anastomótico em cavidade livre.

Os animais A1 II, III e V; A2 II; B1 V, VI e VII; B2 III, IV, V e VII (11 animais) apresentaram abscesso de parede abdominal sob a ferida operatória em 39,2\% do total geral do animais. No grupo de sutura manual a percentagem foi de $28 \%$ (4 animais) e no de sutura mecânica de $50 \%$ (7 animais).

$\mathrm{O}$ animal A2 I apresentou pequena hérnia incisional, o que representa $3,5 \%$ da amostra geral e $7,1 \%$ do grupo manual, enquanto A1 III e A1 V (5,6\% do total e $14,2 \%$ do grupo manual) apresentaram coleção sero-hematíca, de aproximadamente $20 \mathrm{ml}$, perianastomótica, sendo intensa a periviscerite com "bloqueio" da linha de sutura externa destes animais. Observaram-se, ainda diametralmente posicionadas na face externa e interna da linha anastomótica, a presença de linfoadenomegalia e pequena úlcera cicatricial.

Nos animais B1 II, B2 V observou-se linfoadenomegalia justa-anastomótica, mais acentuada que a encontrada no animais do grupo de sutura manual, perfazendo 7,1\% do cômputo total e 14,3\% do grupo de sutura mecânica.

Todos os porcos do grupo A1 e A2 apresentaram granulomas tipo corpo estranho (CE) na linha de sutura.

$\mathrm{O}$ animal A2 II apresentou áreas de infiltrado hemorrágico e ulcerações rasas na linha anastomótica.

Os animais B1 II e B2 V apresentavam ulceração na face interna da linha anastomótica, ao que parece interessando todos os planos. Não obstante em área diametralmente oposta (face externa) observou-se intensa periviscerite aderencial com linfoadenoamegalia justacárdia. Não foram observados sinais de vazamento na prova aérea subaquática nessas peças anatômicas.

Aderências foram encontradas em 13 animais do grupo de sutura manual $(90.2 \%)$ : seis animais do subgrupo de sete dias (Tabela 2) e sete do subgrupo de 14 dias (Tabela 3); em oito animais (57\%) do grupo de sutura mecânica: três animais do subgrupo de sete dias (Tabela 2) e 5 do subgrupo de catorze dias (Tabela 3). Total geral de 21 animais com aderências viscerais (68\%). Restos alimentares (ração) foram encontrados em todos os animais pesquisados.

A diferença média percentual de estenoses ("deltaP") da rafia manual após sete dias foi $25,44 \%$ e após 14 dias, $15,88 \%$. A "delta P" da sutura mecânica foi $22,80 \%$ de estenoses no sétimo dia e $23,4 \%$ no $14^{\circ}$ (Tabela 1 ; Gráficos 1 e 2). 
Tabela 1

Amostragem da estatística básica para cada tipo de sutura considerando as seguintes variáveis quantitativas: diâmetro pré e pós-operatório da cárdia, tempo operatório e peso dos animais

\begin{tabular}{l|r|c|c|c|c|c|c|c}
\hline & \multicolumn{8}{c}{ Tratamentos } \\
\cline { 2 - 9 } Variáveis & \multicolumn{2}{|c|}{ Manual - 07 dias } & \multicolumn{2}{c}{ Manual - 14 dias } & \multicolumn{2}{c}{ Mecânica - 07 dias } & \multicolumn{2}{c}{ Mecânica - 14 dias } \\
\cline { 2 - 9 } & Média & Desvio padrão & Média & Desvio padrão & Média & Desvio padrão & Média & \multirow{2}{*}{ Desvio padrão } \\
\hline Diâmetro pré & 12,86 & 2,03 & 15,14 & 1,57 & 14,86 & 0,90 & 14,57 & 1,27 \\
Diâmetro pós & 9,57 & 2,15 & 12,71 & 1,38 & 11,43 & 0,79 & 11,14 & 1,57 \\
Deltap & 25,44 & 10,74 & 15,88 & 5,92 & 22,80 & 7,49 & 23,04 & 11,92 \\
Tempo operatório & 82,14 & 6,36 & 76,43 & 3,77 & 80,00 & 4,08 & 69,28 & 5,34 \\
Peso & 17,75 & 0,69 & 17,68 & 0,30 & 17,90 & 0,55 & 17,87 & 0,32 \\
\hline
\end{tabular}

Em evidência a diferença percentual média, “delta P”.

Tabela 2

Porcentagem de aderências após 7 dias

\begin{tabular}{l|c|c|c}
\hline & Manual & Mecânica & Total \\
\hline \multirow{2}{*}{ Não } & 1 & 4 & 5 \\
& 14,29 & 57,14 & \\
Sim & 6 & 3 & \\
& 85,71 & 42,86 & 9 \\
Total & 7 & 7 & 14 \\
\hline
\end{tabular}

Tabela 3

Porcentagem de aderências após 14 dias

\begin{tabular}{l|c|c|c}
\hline & Manual & Mecânica & Total \\
\hline \multirow{2}{*}{ Não } & 0 & 2 & \\
& 0,00 & 28,57 & \\
Sim & 7 & 5 & 12 \\
& 100,00 & 71,43 & 14 \\
Total & 7 & 7 & \\
\hline
\end{tabular}

A diferença percentual média do tempo operatório ("delta P" do tempo operatório) foi 82,14 minutos na sutura manual de sete dias e 76,43 minutos na de catorze dias. No grampeamento o tempo ("delta P") no grupo de sete dias foi 80,00 minutos e no de 14 dias foi 69,28 minutos (Tabela 1).

$\mathrm{Na}$ sutura mecânica, em quatro casos do grupo de sete dias e também quatro casos no grupo de 14 dias, observou-se processo flogístico de pequena intensidade. Em um caso de cada subgrupo de animais B1 e B2 (sete e catorze dias) submetidos à rafia com grampeador, observaram-se fragmentos de fio de sutura, provavelmente utilizado para a confecção do chuleio que envolvia as duas peças anastomóticas do grampeador. As anastomoses mecânicas bem coaptadas, microscopicamente apresentavam menor índice de fibrose interanastomótica e razoável reepitelização, sendo bem menor a intensidade de reação granulomatosa

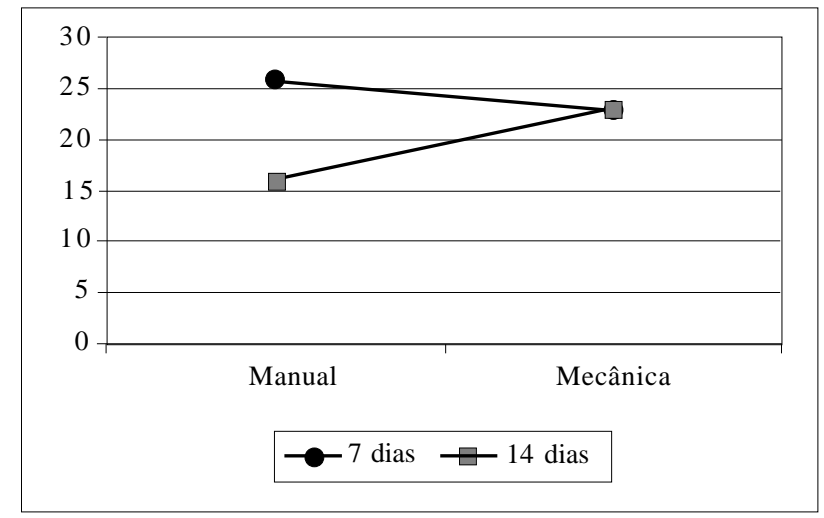

Gráfico 1 - Porcentagens de estenose.

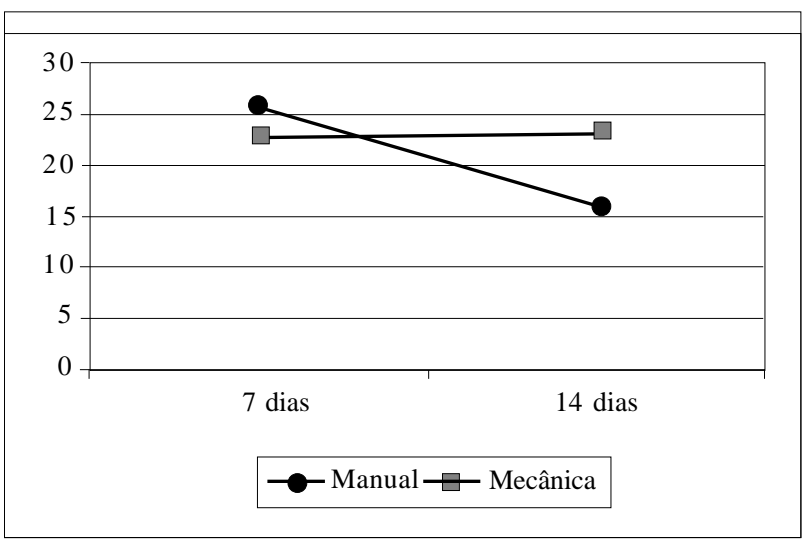

Gráfico 2-Porcentagens de estenose.

do tipo corpo estranho (CE) aos grampos de titânio. As anastomoses com maior grau de fibrose exibiam estreitamento maior quando comparadas com as menos fibróticas.

Cistos epiteliais de retenção com intenso processo inflamatório foram observados na sutura manual em um caso do grupo de sete dias e em outro caso no grupo de 14 dias. Os microabscessos eram muito mais incidentes nas 
suturas manuais do que nas mecânicas, sendo mais encontrados no grupo de sete dias manual.

A neoangiogênese foi significativamente maior nas suturas manuais. O edema perianastomótico também era mais intenso e incidente no grupo dos sete dias das suturas manuais. A sutura manual pareceu propiciar a reepitelização parenquimatosa da mucosa melhor que a observada na sutura mecânica. Essa última comprometeu mais intensa e extensamente a integridade da mucosa. A sutura manual apresentou processo inflamatório granulomatoso do tipo corpo estranho em todos os 14 casos e a proliferação mioblástica (reparo parenquimatoso) foi mais intensa nessa modalidade de sutura (Tabela 2).

Os estudos histopatológicos das peças, segundo a experiência e informação do anatomopatologista, demonstraram uma evolução cicatricial muito semelhante (próxima) a do ser humano.

Relacionando-se a variável qualitativa "aderência" com as suturas pesquisadas (manual e mecânica), organizaram-se tabelas de contigência da ocorrência de aderências por tipo de suturas. As filas referem-se às aderências: "não" e "sim". O número abaixo da freqüência expressa a porcentagem representativa do número (quantidade) de porcos operados que apresentaram, ou não, aderências. $\mathrm{O}$ Teste Exato de Fisher indicou a não existência de evidência estatística $(p$-value $=0,266)$ entre a presença de aderência e o tipo de sutura.

Neste caso, no 14으 dia (Tabela 3) pós-operatório, observa-se que o teste não paramétrico empregado também dá indicação da não evidência de diferença estatística $(\mathrm{p}$ - value $=0,46)$ de dependência entre a presença de aderência e a sutura utilizada. $\mathrm{O}$ nível de significância considerado foi $5 \%(a=0,05)$.

O Gráfico 1 demonstra a relação entre o sétimo e o 14ํ dias para cada tipo de sutura, utilizando-se as médias da variável "DP" (Tabela 1) e o Gráfico 2 a relação entre os tipos de sutura no sétimo e o $14^{\circ}$ dias. Pode-se constatar em ambos os gráficos que a média de estenose para a sutura manual no sétimo dia pós-operatório foi $25,44 \%$ e no 14 o dia $15,88 \%$. A média de estenose para a sutura mecânica no sétimo e $14^{\circ}$ pouco variou, $22,80 \%$ e $23,04 \%$.

De maneira sucinta e conclusiva, os resultados dos testes estatísticos não paramétricos demonstraram a não significância estatística dos fatores tipo de sutura e quantidade de dias na porcentagem de estenoses ("DP") apresentada pelos animais.

Observou-se secção de continuidade anastomótica na peça referente ao animal A 1 III que apresentava um segmento anastomótico com bordas não coaptadas (deiscência parcial) e não reepitelizado. O selamento dessa anastomose era sustentado por proliferação do estroma conjuntivo oriundo de bloqueio visceral contíguo.

As peças dos animais B1 II e B2 V exibiam intensa reação linfo-histiocitária (linfonodos) bloqueando uma deiscência parcial na linha de sutura posterior, face externa (cárdia).

\section{DISCUSSÃo}

Segundo a literatura revisada, há aproximadamente quatro décadas, a sutura em dois planos era firmemente defendida pela maioria das escolas cirúrgicas, entretanto, a partir de 1951, foram relatados bons resultados com as suturas gastrointestinais em um plano ${ }^{9,19,20}$. Desde então, as anastomoses viscerais do sistema digestório têm sido realizadas predominantemente em um plano, sero-seroso extramucoso $^{1,6,8,21}$, confirmando os resultados satisfatórios.

"Certo é que, ambas as técnicas possuem fraquezas potenciais que podem comprometer uma anastomose" ${ }^{3}$.

Quanto aos fios empregados nessas suturas, apesar das opções atuais, afirma-se ${ }^{1}$ que não existe um material de sutura único que seja ideal. Esses autores acrescentam que: "Dependendo do tipo e da extensão da ferida, dos tecidos envolvidos e da capacidade (biológica) individual de cicatrização, as exigências para a sutura diferem acentuadamente".

É bastante conhecida a maior probabilidade de infecções dos fios multifilamentares e a suscetibilidade à ruptura, principalmente os trançados, quando expostos às forças de cisalhamento. Os monofilamentares, apesar de menos propensos às infeções e ao cisalhamento, são mais sujeitos ao dano pelo enfraquecimento e à ruptura em razão da manipulação grosseira e do uso pouco criterioso do instrumental cirúrgico. Ideal seria se o material de sutura escolhido pudesse tornar a sutura tão resistente quanto o tecido intacto ${ }^{1,3}$. "A qualidade que favorece a utilização de fios inabsorvíveis nas anastomoses gastrointestinais é a retenção prolongada da força tensional, que exclui a falha de sutura como possível causa de deiscência" ${ }^{3}$.

Neste trabalho, a opção pelo fio de poliglactina 910 (Vicryl) $\mathrm{n}^{\circ} 000$, justificou-se pela menor incidência de vazamento das anastomoses suturadas com esse fio (poliglactina) relatada $^{5}$, e pelo estudo multicêntrico de 790 casos, onde também utilizou-se a poliglactina 910 (Vicryl) do grupo OESO, 1986. Tais considerações foram ratificadas pelos resultados histológicos encontrados na presente pesquisa que demonstraram ser o tempo de cicatrização da anastomose suína muito próximo ao do ser humano. Parece que o tempo de vida média (vida média do porco $=72$ semanas) não exerce marcante influência no tempo de cicatrização.

Os grampeadores cirúrgicos evoluíram e muito têm contribuído para o aprimoramento da técnica operatória anastomótica. Apesar de tornarem o procedimento cirúrgico mais fácil, eles não substituem os princípios da boa técnica cirúrgica ${ }^{3}$. Desde a nova era das anastomoses mecânicas, iniciada com os trabalhos de Steinchen e Ravitch, na década de $50^{22}$ e Androssov, na de $70^{16}$, até as mais recentes publicações ${ }^{6,17,23-25}$ estabeleceu-se uma profícua polêmica quanto à segurança, economia, rapidez e grau de complicações, mormente no que tange às fístulas e estenoses, decorrentes de ambos os tipos de anastomoses (manual e mecânica). Todavia, a partir de $1984^{26}$, justifica-se a preferência pelas anastomoses mecânicas através da demonstração em cães com o fluxo arterial marcado ( I-125), a ocorrência de menor isquemia, necrose tecidual menos intensa e neo-angiogênese mais acentuada nas 
suturas mecânicas ${ }^{26,27}$. Entretanto, em outra pesquisa em cães, observou-se que a anastomose mecânica provocou maior isquemia nas bordas viscerais anastomosadas ${ }^{24}$, coincidente com nosso experimento.

Quanto ao aço inoxidável usado nos grampos, causa menos aderências e produz menor resposta inflamatória ${ }^{3}$, concordantes com o observado nesta pesquisa (Tabelas 2 e 3 ).

No presente trabalho optou-se pelo grampeador intraluminal (ILS) carregado com 16 grampos de titânio medindo 4,5 milímetros. O diâmetro da cabeça do grampeador escolhido media 21 milímetros por ser o mais compatível com o calibre esofagiano do animal de experiência utilizado. A forma e dimensões do aparelho foram bastante satisfatórias (Figura 1).

Quanto ao método de aferição dos diâmetros pré (anatômico) e pós-operatório, a utilização de um balonete de látex inflado com alginato (Figura 2) foi um recurso, salvo melhor juízo, original, bastante fidedigno, de baixo custo, de simples e fácil avaliação e guarda para posteriores estudos (contraprova).

Quanto à análise estatística multifatorial não houve influência das variáveis biológicas intercorrentes, sendo os fatores técnicos os mais importantes para a boa cicatrização das anastomoses manuais e mecânicas ${ }^{22,26}$, fatos não confirmados por outros autores ${ }^{5,6}$ pois consideram quinze fatores determinando vazamento e estenose das anastomoses esofagogástricas manuais e mecânicas.

Nosso trabalho permite considerar insignificante a diferença estatística das estenoses em ambos os tipos de anastomoses, coincidente com outros autores ${ }^{18}$. As diferenças percentuais médias dos tempos operatórios ("deltas P do tempo operatório") foram bastante próximas. $\mathrm{Na}$ sutura manual e mecânica, no subgrupo de sete dias (A1 e B1), essas foram 82,14 minutos e 80,00 minutos, respectivamente, pouco maiores que as obtidas na sutura manual (76,43 minutos) e na mecânica $(69,28$ minutos) de 14 dias. O menor tempo operatório entre os subgrupos de sete e 14 dias, mesmo que pequena a diferença e estatisticamente não significante, talvez se explique pelo melhor desempenho (experiência) do cirurgião mais familiarizado com a técnica operatória, "não existindo nenhum substituto para uma técnica cirúrgica correta" ${ }^{27}$.

A pesquisa em pauta demonstrou que houve considerável diminuição pós-operatória do diâmetro anatômico da cárdia em $100 \%$ dos grupos de animais submetidos à rafia manual e mecânica. Contudo, o estreitamento da luz anastomótica não prejudicou o trânsito alimentar alto. $\mathrm{Na}$ verdade, o que se procurou no presente trabalho foi comparar o percentual médio da diferença entre o diâmetro pré e pós-operatório da cárdia (“delta P”)-(Tabela 1). Neste mister observou-se que a média percentual de estenose, entre ambas as técnicas em epígrafe, foi muito próxima e, portanto, estatisticamente desprezível, concordante com outros autores ${ }^{16,28}$.

Quanto às aderências, somente a boa técnica cirúrgica não previne a formação de aderências, principal motivo de terapia cirúrgica, mas também a magnitude da cirurgia, tempo operatório, manipulação das vísceras, infecção, fios de sutura, sangramentos, sexo, idade e doenças intercorrentes ${ }^{29}$.

O presente trabalho demonstrou a incidência de $90,2 \%$ de aderências no grupo de sutura manual e $57 \%$ no de sutura mecânica, com o total geral de $68 \%$ (Tabelas 2 e 3 ) . O maior percentual estatístico de aderências do grupo manual, talvez, tenha decorrido da maior reação inflamatória suscitada pela presença do fio de sutura, agindo como corpo estranho (CE) e por possíveis microvazamentos nos espaços interpontos.

Demonstrou-se que o percentual médio da diferença entre os diâmetros pré e pós-operatórios ("delta P") não foi influenciado estatisticamente pela maioria das variáveis consideradas, com exceção do número de dias na sutura manual. Nesse caso observou-se maior média percentual de estreitamento no grupo de sutura manual de sete dias, 25,44\%, sendo que a média (delta $\mathrm{P}$ ) dos 14 dias foi $15,88 \%$. Quanto aos subgrupos da sutura mecânica (sete e $14^{\circ}$ dias), não se observou diferença estatística, $22,80 \%$ e $23,04 \%$, respectivamente. Provavelmente o maior índice estenótico no subgrupo de sete dias da sutura manual, decorra do edema flogístico ainda não totalmente reabsorvido, nesse período de tempo (sete dias).

Observou-se que as peças anatômicas referentes aos animais B1 II e B2 V (anastomoses mecânicas) apresentavam três importantes aspectos: 1) macroscopicamente, possuíam maior índice estenótico; 2) microscopicamente, viu-se que as bordas anastomóticas esofagogástricas dessas peças, em determinada área, não se encontravam devidamente coaptadas (deiscência parcial); 3) havia um espaço interanastomótico preenchido por tecido fibroso, denotando franca cicatrização por segunda intenção, sem contudo ocorrer secção de continuidade na face externa da anastomose. Nesse caso, a serosa gástrica encobria a linha anastomótica externa e os tecidos muscular e mesotelial, respectivamente, serviram de substrato para a cicatrização fibrótica centrípeta.

Talvez "o calcanhar-de-Aquiles das anastomoses mecânicas" com estenose e presença de vazamento possa ser explicado pelos dois tipos de cicatrização, neste trabalho observados, isto é, menor coaptação das bordas e maior fibrose. A aproximação maior das bordas resulta em melhor epitelização, menor retração cicatricial e logicamente mínima estenose. Essas deduções se amparam e concordam com os atuais conhecimentos sobre a cicatrização dos tecidos ${ }^{25}$. Teoricamente, baseados nesses achados histológicos, pode-se afirmar o óbvio: se a reepitelização total for conseguida, certamente não haverá complicações anastomóticas ${ }^{29-31}$.

Do exposto e discutido, parece ter sido demonstrado que a evolução tecnológica não conseguiu ainda superar a experiência do cirurgião e a boa técnica operatória como garantia da excelência anastomótica. Entretanto, o avanço tecnológico, observado nos demais campos da atividade humana, exerce também importante influência na evolução das ciências médicas. Sem dúvida, grampeadores mais elaborados, colas biológicas e outros futurísticos artefatos serão corriqueiros instrumentos no arsenal cirúrgico de um porvir não muito distante. 
Em síntese, concluem os autores que a estenose foi diretamente proporcional à falha anastomótica, sendo o limite estenótico das anastomoses, sem prejuízo do trânsito alimentar, a redução de $25,44 \%$ do diâmetro anatômico. Quanto ao delta $\mathrm{P}$ de estenose para os subgrupos de sutura manual e mecânica e aquele dos tempos operatórios foram estatisticamente iguais. Entretanto, o delta $\mathrm{P}$ de estenose do grupo de sutura manual de sete dias foi maior que o do grupo de 14 dias.

\begin{abstract}
Twenty eight pigs were randomly distributed to two groups of 14 animals (" $A$ " and " $B$ "). Cardia's anatomic diameter was mouldred and measured with a small latex balloon filled with alginato injection. The animals were then submitted to an esophagogastric section. In group " $A$ ”, anastomosis was performed with separated sutures using 910 poliglactina "000" and in the group " $B$ " the suture was performed with ILS stapler. Seven pigs, from both subgroups "Al" and "Bl", were submitted to a new operation and evaluated after seven days while two other sub-groups from seven animals each ("A2" and "B2") had the operation on the $14^{\text {th }}$ day. The anatomic parts were macroscopically examined, followed by a pressure test, histological study and the identification and measurement moulds. The medial percentual difference of stenosis (delta P), was evaluated by the media of the cardias' diameter before and after manual and mechanics suture. Statistical analysis showed that there is no significant percentual media difference of stenosis and operative time ("deltas Ps"). The "delta P" stenosis in the manual suture was $25,44 \%$ at the $7^{\text {th }}$ postoperative day and $15,88 \%$ at the $14^{\text {th }}$ postoperative day. In the mechanics suture the percentual on the $7^{\text {th }}$ and $14^{\text {th }}$ day were $22,80 \%$ and $23,04 \%$. The stenosis did not cause any trouble to the esophagogastric alimentary transit. Macroscopically, there were no free leakage observed in the abdominal cavity, although the microscopic evaluation showed a blocked partial suture ruptures in three animals. Adesions were more prevalent with manual sutures. A bad coaptation between visceral edges of the anastomosis in a few clippings resulted in a fibriform reparation with areater stenosis. Regarding hand made sutures, more perianastomotic inflamatory changes were observed in this subset of animals, while the stapling of the anastomosis lowered angiogenesis. The present study may have demonstrated that manual and mechanical sutures, if not ideal are at least, satisfactory and have considerable quality when they are performed with minimal trauma, good hemostasis, preservation of the blood irrigation, infection control, choice of the appropiated suture material or the most suitable stapler with good coaptation of the visceral edges.
\end{abstract}

Key Words: Esophagogastric stenosis; manual and mechanic sutures.

\section{REFERÊNCIAS}

1. Spotnitz WD, Falstron JK, Rodeheaver GT - Papel dos Fios de Sutura e da Cola ( Selante) de Fibrina na Cicatrização das Feridas. Clin Cir Am N 3: 647-665. Lee RB, Miller JI - Esofagectomia para câncer. - Clin Cir Am N 1997; 5:1151-76.

2. Hendriks T, Mastboom WJB - Healing of experimental intestinal anastomosis: early events. Exp Mol Pathol 1985;42:411-15.

3. Thornton FJ, Barbul AC - Cicatrização no trato gastrointestinal - Clin Cir Am N 1997; 3: 547-70.

4. Barroso LF, Pessôa RF, Filho AO, Saboya CJ et al. - Sutura digestiva por chuleio contínuo em plano único. Rev Col Bras Cir 1987; 14: 121-6.

5. Dewar L, Gelfand G, Finley RJ, et al. - Factors affecting cervical anastomosis leak and stricture formation following esophagogastrectomy and gastric tube interposition. Am J Surg 1992; 163: 484-9.

6. Bardini R, Bonavina L, Asolati M et al. - Single-layered cervical esophageal anastomoses: A prospective study of two suturing techniques. Am Thorac Surg 1994; 4: 1087-90.

7. Mantovani M, Medeiros RR. Leonardi LS - Sutura seromuscular extramucosa em um plano único na cirurgia do intestino. Rev Paul Med 1975; 86: 123-30.
8. Leonardi LS, Mantovani M, Alcântara FG et al. - Estudo comparativo entre suturas em um plano único e em dois planos no intestino delgado na vigência de peritonite: trabalho experimental no cão. Rev Paul Med 1977; 89:.511.

9. Kunzle JE, Ziliotto Jr A - Estudos das anastomoses esofágicas cervicais após esofagectomia. Rev Col Bras Cir 1985; 12: 42-6.

10. Sayeg F, Joppert Filho W, Jazbik A et al. - Esofagectomia sem toracotomia com reconstrução pela esofagogastroplastia pré-esternal em um só tempo. Rev Bras Cir 1988; 78: 221-25.

11. Nigro AJT - Anastomose Esôfago-Esofágica Cervical por invaginação. Estudo Experimental em Cães. Acta Cir Bras 1996; 11: 63-75.

12. Barros MEPM, Módena JLP, Ferreira AL - Estudo comparativo de diferentes fios de sutura em anastomoses do esôfago cervical do cão. Rev Bras Cir 1987;77: 273-8.

13. McKeown KC - Total three stage oesophagectomy for cancer of the oesophagus. Br J Surg 1976; 63: 259-62.

14. Hermreck AS, Crawford DG - The esophageal anastomotic leak. Am J Surg 1976; 132: 794-8.

15. Steichen FM, Ravitch MM - History of mechanical devices and instruments for suturing Surg. Curr Probl Surg 1982; 19: 381-90.

16. Von Petz A - Zur Technik der Magenresektion. Ein neuer Magen-Darnmähapparat. Zentralbl Chir 1924; 51: 179- 
88. - Apud- Steichen FM, Ravitch MM - Instrumentos de Grampeamento Contemporâneo e Técnicas Básicas de Sutura Mecânica. - Clin Cir Am N 1984; 3: 447-62.

17. Androssov PI - Experience in the application of the instrumental mechanical suture in surgery of the stomach and rectum. Acta Chir Scand 1970; 136: 57-63.

18. Brenner S, Malafaia Moraes RS, Bakonyi Neto A - Uso do "stapler" em anastomoses gastrointestinais. Rev Bras Cir 1981; 71: 23-5.

19. Aquino JLB. Sutura manual e mecânica da anastomose esofagojejunal. Análise clínica em 38 Gastrectomias totais.Tese (Mestrado). Faculdade de Ciências Médicas da Universidade Estadual de Campinas, 1990, 140p.

20. Gambee LP, Garngobst W, Hardwich CE - Ten years experience with a single layer anastomosis in colon surgery. Am J Surg 1956; 92: 222-7.

21. Inácio W, Margarido NF, Pereira V, Rahal F - Anastomose esôfago-esofágica cervical com adesivo butil -2 - cianoacrilato e fio de algodão em dois planos de sutura.Rev Col Bras Cir 1987; 14:101-4.

22. Steichen FM, Ravitch MM - Mechanical sutures in esophageal surgery. Ann Surg 1980; 191:373-81.

23. Reis Neto JA - Sutura Mecânica em Cirurgia Digestiva. Rev Goian Med 1992; 38: 15-8.

24. Caparossi C - Anastomose esofágica manual e mecânica. Estudo experimental em cães.- Tese (Mestrado). Faculdade de Medicina da Universidade de São Paulo 1996, 134p.

25. Iannettoni MD, Whyte RI, Orringer B - Catastrophic complications of the cervical esophagogastric anastomosis. J Thorac Cardiovasc Surg 1995; 110:1493-1501.

26. Peracchia A, Bardini R, Ruol A et al. Esophagovisceral anastomose leak.-A prospective statiscal study of presdisposing factors.-J Thorac Cardiovasc Surg 1988; 95: 685-91.
27. Dunphy JE, Jackson DS - Practical applications of experimental studies in the care of primarily closed wound. Am J Surg 1962; 104: 273-7.

28. Basso N, Minervini S, Marcelli M et al. - A technical aid in stapled esophageal anastomosis. Surg Ginec \& Obst 1988; 167:525-6.

29. Patil PK, Patel SG, Mistry RC et al. - Cancer of the esophagus: esophagogastric anastomotic leak. A retrospective study of predisposing factors.-J Surg Oncol 1992; 49: 163-7.

30. Pierie JPEN, De Graaf PW, Poen H et al. - Incidence and management of benign anastomotic stricture after cervical oesophagogastrostomy. Br J Surg 1993; 80: 471-4.

31. Wheeless CRJR., Smith JJ - A comparison of the flow of iodine 125 through different intestinal anastomoses: standard, Gambee or staples. Surg Gynec \& Obst 1983; 62:513-7.

\section{ENDEREÇO PARA CORRESPONDÊNCIA:}

Prof. Abrão Rapoport

Praça Amadeu Amaral, 47 - conj. 82

01327-010 - São Paulo-SP. 